\title{
Pensando o Ano Europeu do Desenvolvimento: Oportunidades e Limitações Ante a Claúsula Democrática Firmada na União Europeia
}

\author{
Linara Oeiras Assunção \\ Professora-assistente do curso de Direito da Univer- \\ sidade Federal do Amapá. Doutoranda em Direito pela \\ Universidade Federal de Minas Gerais. Mestre em Direito \\ Ambiental e Políticas Públicas pela Universidade Federal \\ do Amapá. lioeiras@hotmail.com
}

\section{Jessica Ramos da Silva}

Advogada inscrita na Ordem dos Advogados do Brasil (Seccional Amapá) e na Ordem dos Advogados Portugueses. Mestranda em Ciências Jurídico-Políticas pela Faculdade de Direito da Universidade de Lisboa. jessicaramosms@gmail.com

\section{Resumo}

0 ano de 2015 foi a reta final para as metas fixadas pela Organização das Nações Unidas para a concretização dos Objetivos de Desenvolvimento do Milênio e de negociação da agenda pós-2015. Nesse clima, a União Europeia (UE) firmou o "Ano Europeu do Desenvolvimento" (AED). Durante os 12 meses de 2015 foram propostas ações voltadas à redução da pobreza no mundo e às relações da UE com os países em desenvolvimento. Em um contexto de decrescimento do Produto Interno Bruto em diversas regiões da Europa, de desemprego, de restrição aos apoios sociais, de austeridade, de agravamento das desigualdades, porém, foi difícil perceber o AED como uma iniciativa exclusivamente voltada ao exterior. Então, o que significou, diante de retrocessos em direitos fundamentais nos países europeus em crise, 2015 ser o Ano Europeu do Desenvolvimento? Uma oportunidade da UE reafirmar sua imagem como um dos principais agentes mundiais na luta contra a pobreza? $\mathrm{Ou}$ uma oportunidade de combater a intensificação das desigualdades internas e fazer valer a cláusula democrática firmada pelos países europeus que os obriga a promover a democracia e a respeitar os direitos humanos? Para nortear esta discussão, utilizou-se o paradigma integracionista da Constituição da UE, do Direito Comunitário e também a própria compreensão da cláusula democrática. 
Quanto à metodologia, a pesquisa seguiu uma abordagem qualitativa, com enfoque compreensivo, pautada em revisão bibliográfica. 0 estudo concluiu que o AED abriu oportunidades para a UE (re) pensar suas políticas públicas internas de cooperação e re(pensar) o uso da cláusula democrática para fins de proibição de retrocesso em termos de direitos humanos.

Palavras-chave: União Europeia. Ano europeu do desenvolvimento. Cláusula democrática.

\title{
Thinking About the European Year of Development: Opportunities and Limitations of The Democratic Clause Signed in The European Union
}

\begin{abstract}
The year 2015 was the final stretch to the targets set by the United Nations for the achievement of the Millennium Development Goals and negotiating the post-2015. In this climate, the European Union signed the "European Year of Development". During the 12 months of 2015 were proposed actions to contribute to poverty reduction in the world and meet the EU's relations with developing countries. However, in a decrease context of gross domestic product in various regions of Europe, unemployment, restriction of social support, austerity, widening inequalities, it was difficult to understand that the European Year of Development has been exclusively initiative to the outside. So, what has meant, in the face of setbacks in fundamental rights in European countries in crisis, 2015 being the European Year of Development? An opportunity for the EU to reaffirm its image as one of the world's leading players in the fight against poverty? Or it an opportunity to combat the intensification of internal inequalities and to enforce the democratic clause signed by the European countries which obliges them to promote democracy and respect human rights? In order to guide this discussion, the integrationist paradigm of the EU Constitution, of Community Law was used, as well as the very understanding of the democratic clause. As for the methodology, the research followed a qualitative and comprehensive approach, based on a bibliographic review. The study concluded that the European Year of Development has opened up opportunities for the EU to (re) think about its internal public policies of cooperation and (re) think the use of the democratic clause for the purpose of prohibiting setback in terms of human rights.
\end{abstract}

Keywords: European Union. European year of development. Democratic clause.

Recebido em: 23/8/2016

Revisões requeridas em: 16/10/2017

Aceito em: 1。/11/2017

\section{Sumário}

1 Introdução. 2 Considerações sobre o direito comunitário na União Europeia. 3 0s compromissos do ano europeu do desenvolvimento (2015) e suas implicações. 4 A ponderação da cláusula democrática para a garantia de direitos humanos diante da crise europeia. 5 Conclusão. 6 Referências. 


\section{INTRODUÇÃO}

Ao longo das últimas décadas, as condições de vida das populações europeias degradaram-se, com elevadas percentagens de desemprego, nomeadamente duradouro, atingindo vários níveis etários. A insegurança, a incerteza em relação ao futuro, a separação entre sociedade civil e Estado aumentaram, e reduziu-se a coesão social, retomando erros já cometidos quando da crise de 1929-1933. Adotou-se uma política restritiva e esqueceu-se, com uma amnésia profunda, o que Keynes e muitos outros economistas já tinham debatido: "A dinâmica de dependência dos mercados financeiros reforça a degenerescência das relações éticas na atividade econômica, na política e na sociedade” (PIMENTA, 2015, p. 17).

Para exemplificar, em 2014 a desigualdade entre ricos e pobres nos 34 países membros da Organização para a Cooperação e Desenvolvimento Econômico (Ocde) atingiu o nível mais elevado em 30 anos, de acordo com Cingano (2014).

Vigevani e Aragusuku (2013) acreditam que a crise em curso na União Europeia trouxe como consequência o aumento do debate sobre a capacidade do bloco regional de atenuar as desigualdades entre os países e também entre as regiões dentro de cada país.

Nesse contexto, este trabalho tem o objetivo de debater acerca das seguintes questões: $\mathrm{O}$ que significou, diante de retrocessos em direitos fundamentais nos países europeus em crise, 2015 ser o Ano Europeu do Desenvolvimento? Uma oportunidade de a União Europeia reafirmar sua imagem como um dos principais agentes mundiais na luta contra a pobreza? Ou uma oportunidade de combater a intensificação das desigualdades internas e fazer valer a cláusula democrática firmada pelos países europeus que os obriga a promover a democracia e a respeitar os direitos humanos? 
Para nortear esta discussão utiliza-se o paradigma integracionista da Constituição da União Europeia, do Direito Comunitário e também a própria compreensão do que vem a ser a cláusula democrática. Quanto à metodologia, a pesquisa segue uma abordagem qualitativa, com enfoque compreensivo, pautada em revisão bibliográfica.

Desta feita, os argumentos ora defendidos encontram-se centrados em três momentos: a) Considerações sobre o Direito Comunitário na União Europeia; b) Os compromissos do Ano Europeu do Desenvolvimento - 2015 e suas implicações; e c) A ponderação da cláusula democrática para a garantia de direitos humanos diante da crise europeia.

Espera-se, ao final, trazer algumas reflexões e contribuições a respeito de um possível futuro para a Europa, na tentativa de resgatar o espírito de solidariedade no âmbito interno que parece ter-se perdido com o passar dos anos. Ademais, espera-se ponderar sobre algumas oportunidades e limitações ante a cláusula democrática firmada na União Europeia, diante da possibilidade de ela auxiliar na proibição de retrocesso em termos de direitos humanos.

\section{CONSIDERAÇÕES SOBRE O DIREITO COMUNITÁRIO NA UNIÃO EUROPEIA}

Inicialmente, cabem algumas considerações a respeito do Direito Comunitário Europeu, que é “constituído pelo conjunto de normas jurídicas que regulam as relações entre os Estados membros da União Europeia” (LIMA FILHO, 2006, p. 75).

Este conjunto de normas é composto por dois grandes substratos:

a) O Direito originário, que é integrado pelos tratados constitutivos da União com seus complementos e modificações; 
b) O Direito derivado, que é constituído pelas normas emanadas dos órgãos da União com competência legislativa, quais sejam, a Comissão e o Conselho.

É oportuno lembrar que a União Europeia (UE) surgiu após a Segunda Guerra Mundial, principalmente porque os países se encontravam em um momento delicado econômica e militarmente. Em um primeiro momento, contava-se com a presença da Comunidade Europeia do Carvão e do Aço (Ceca), criada pelo Tratado de Paris, em 1951, formada pela França, Alemanha, Itália, Países Baixos, Bélgica e Luxemburgo. Posteriormente, estabeleceu-se a criação da Comunidade Econômica Europeia (CEE) e a Comunidade Europeia da Energia Atômica (Ceaa), ambas originadas pelo Tratado de Roma, em 1957, formadas pela Alemanha, Bélgica, França, Itália, Luxemburgo e Países Baixos (MARTINS, 2009).

Para Lewandowski (1997), o surgimento da União Europeia tratou-se de uma significativa mudança na natureza de uma associação, sendo nítida a diferença quando comparada a uma simples organização internacional, principalmente no tocante à particularidade do relacionamento entre os seus Estados-membros.

Pois bem, a UE exerce funções próprias dos Estados, sobretudo pela presença de instituições que possuem um poder legislativo, autoridades administrativas e órgãos jurisdicionais, quais sejam, o Conselho Europeu, o Parlamento Europeu, o Conselho de Ministros, a Comissão Europeia, o Tribunal de Justiça e a Corte de Contas. Ainda, entretanto, que presentes diversas características semelhantes, a UE não é um Estado stricto sensu, constituindo-se em um organismo supranacional e soberano (LEWANDOWSKI, 1997).

O Direito Comunitário é um conjunto de regras e princípios que regem a estrutura da União Europeia, a qual se constitui como uma ordem jurídica comunitária independente e autônoma em relação aos Estados que 
a compõem. Desta forma, encontra na teoria da soberania compartilhada, segundo a qual os Estados membros cedem parte do seu poder para a UE, a base do Direito Comunitário (M. JÚNIOR, 2011).

Lima Filho (2006) ressalta que o Direito Comunitário não objetiva substituir o direito nacional de cada Estado, considerando que a característica da supranacionalidade deverá ser interpretada de forma que, dentro do ordenamento jurídico de cada Estado-membro, também deverão ser respeitadas as demandas do direito estatal.

Martins (2009) pondera que o Direito Comunitário possui cinco princípios basilares, quais sejam:

a) Autonomia: a elaboração das normas comunitárias é competência de instituições próprias da UE, e serão normas dotadas de autonomia diversa das normas de direito interno, mesmo quando integradas em uma ordem jurídica nacional;

b) Primazia: posto tratar-se de uma ordem jurídica supranacional com precedência absoluta em relação ao direito interno;

c) Unidade: as normas do direito comunitário deverão ser introduzidas no ordenamento jurídico dos Estados-membros, prevalecendo a Unidade do Direito Comunitário;

d) Aplicabilidade imediata: as normas de direito comunitário não precisam ser ratificadas para que vigorem;

e) Efeito de direito das normas: os direitos e deveres constantes em documentos originários do Direito Comunitário podem ser suscitados em litígios entre cidadãos e Estados-membros.

Nesse sentido, Lewandowski (1997) aponta como pedras de toques do Direito Comunitário a aplicabilidade direta e a supremacia das normas comunitárias sobre o direito interno, além de considerar a autonomia da ordem jurídica comunitária e a cooperação entre o ordenamento comunitário e interno como os princípios mais importantes desse ramo do direito. 
No que diz respeito à primazia das normas comunitárias ante as normas de direito interno, o artigo 234 do Tratado da Comunidade Europeia dispõe que, na hipótese de conflitos de normas anteriores ao tratado, as incompatibilidades deverão ser eliminadas, sendo insuficiente a não aplicação da norma interna contrária.

Lima Filho (2006) frisa a relevância de considerar as mudanças no campo internacional e a consolidação de grandes espaços econômicos no estudo do Direito Comunitário. Para o autor, as culturas das populações locais devem ser observadas, bem como tradições constitucionais democráticas e sistemas jurídicos em prol do pleno exercício dos direitos e deveres da cidadania, objetivando o bem comum.

Faz-se imperioso sublinhar que o Direito Comunitário possui a habilidade de ofertar proteção e proporcionar segurança ao processo de integração com a valorização da dignidade humana, de modo a auxiliar na construção de uma sociedade democrática, fraterna e solidária (LIMA FILHO, 2006).

Feitas essas considerações notadamente sobre os aspectos positivos de se constituírem os Estados em torno de um Direito Comunitário, apresentam-se ideias sobre os desafios de uma relação horizontal.

\section{OS COMPROMISSOS DO ANO EUROPEU DO DESENVOLVIMENTO (2015) E SUAS IMPLICAÇÕES}

A Cimeira do Milênio das Nações Unidas, que ocorreu no ano 2000 em Nova Iorque, aprovou a Declaração do Milênio das Nações Unidas, documento que refletiu as preocupações de 189 Estados membros das Nações Unidas, sendo 147 representados por seus Chefes de Estado (NAÇÕES UNIDAS, 2000). 
Foram acordados os Objetivos de Desenvolvimento para o Milênio (ODM), sendo compromisso dos líderes mundiais buscar concretizar, até 2015, os seguintes objetivos:

a) erradicar a pobreza e a fome;

b) assegurar uma educação básica para todos;

c) promover a igualdade de gênero e a emancipação das mulheres;

d) reduzir a mortalidade infantil;

e) melhorar a saúde materna;

f) combater o VIH/Sida, a malária e outras doenças;

g) assegurar a sustentabilidade ambiental;

h) estabelecer uma pareceria mundial para o desenvolvimento.

Em 2015, a União Europeia escolheu como tema de ação “Ano Europeu do Desenvolvimento" (AED 2015). Com o lema “O nosso mundo, a nossa dignidade, o nosso futuro”, durante os 12 meses do ano foram propostos ações e debates com o intuito de conhecer as relações da União Europeia com os países em desenvolvimento, além de debaterem formas de contribuição para a redução da pobreza e o apoio às pessoas daqueles países (PARLAMENTO..., 2015).

Ressalta-se que é inegável a importância da União Europeia no cenário mundial, tanto economicamente quanto no que diz respeito a questões políticas. Restam-nos dúvidas, entretanto, no que corresponde ao papel da UE em outras questões internacionais, e não apenas num contexto comunitário europeu, ou seja, a atuação externa da UE. 
Não obstante, parece-nos que um estudo acerca do AED 2015, bem como dos seus principais desafios sociais e jurídicos, não estaria completo sem uma abordagem, ainda que breve, no que corresponde à posição da UE como sujeito de Direito Internacional Público e sua ação na cena mundial.

Nesse sentido, cumpre-nos destacar a indicação de Queiroz (2009), segundo a qual é a partir da constituição das organizações internacionais de natureza política e vocação universal que a sociedade internacional passa a desenvolver um nível de institucionalização e organização que não leva em consideração apenas os interesses primários dos Estados, o que conduz a uma maior interação e interdependência entre o direito internacional e o direito interno dos Estados.

Dessa forma, o aparecimento das organizações internacionais que, em um primeiro momento, restringiam-se a matérias de natureza administrativa ou fluvial e, posteriormente, política e de vocação universal, trouxe a cooperação para o plano das preocupações gerais, fornecendo um quadro propício para a mutação da sociedade e de direitos internacionais (QUEIROZ, 2009). Resta assente que, atualmente, o direito internacional tem como fulcro a cooperação internacional entre os Estados e as organizações internacionais.

A Carta das Nações Unidas seria um exemplo notável disso, já que tem como um dos seus objetivos principais a cooperação internacional, a qual, em conjunto com uma política de desenvolvimento, constituiriam instrumentos de manutenção da paz, segurança e justiça internacionais (QUEIROZ, 2009). Nos ditames do artigo 1ำ/3 do referido documento, é um propósito das Nações Unidas conseguir uma cooperação internacional para resolver os problemas internacionais de caráter econômico, social, cultural e humanitário, e para promover e estimular o respeito aos direitos humanos e às liberdades fundamentais para todos, sem distinção de raça, sexo, língua ou religião. 
Duarte (2014) indica que a Carta das Nações Unidas é instrumento capaz de revelar o anseio de delimitar e efetivar um determinado programa de ação de desenvolvimento da sociedade internacional, tratando-se, sob uma ótica pós-moderna e neocontratualista, de um fundamento do Direito Internacional Público, como também resultado da necessidade de garantir a existência da sociedade internacional no plano político-institucional.

Para a autora, o Direito Internacional encontra-se no segundo estágio de sua existência, um momento mais exigente e sofisticado, no qual vincula e limita a vontade dos sujeitos internacionais. $\mathrm{O}$ respeito aos valores suprapositivos, da garantia da paz e do respeito pela dignidade da pessoa humana, trata-se de um dever civilizacional e humanista, além de possuir uma relação de cumplicidade finalística. A promoção do desenvolvimento social e humano, por exemplo, por meio do combate à pobreza extrema e desigualdade, são vetores interdependentes de realização das condições objetivas de consolidação e exercício dos direitos humanos (DUARTE, 2014).

Queiroz (2009) entende que o Direito Internacional Econômico também corresponde, em certo ponto, ao direito internacional do desenvolvimento, em virtude de possuir um conteúdo transversal. Ademais, chama-nos a atenção para que se tenha em consideração a circunstância de unidade sobre a qual repousa o sistema internacional, esbarrando em diversos desafios.

Pondera a autora que o reconhecimento dos "direitos do homem" deve ser considerado uma regra primordial do direito internacional e requer a adesão de todos os Estados independentemente do respeito pelo seu “domínio reservado" ou esfera de “jurisdição interna”. Questões como a proliferação das ameaças globais e transnacionais, os danos ambientais, o fluxo migratório, a expansão da população, a doença e a fome, o terrorismo e o crime organizado, figuram como problemáticas que devem ser debatidas e freadas (QUEIROZ, 2009). 
Sobre o assunto, Gouveia (2014) disserta que o Direito Internacional Econômico e do Desenvolvimento é o capítulo jurídico-internacional que enquadra as relações econômicas internacionais e que produz as regras que se destinam a estimular o desenvolvimento, econômico e social dos Estados do Terceiro Mundo.

De modo similar, temos o Direito Internacional da Cooperação, o qual disciplina as relações de ajuda dos Estados ricos e das organizações internacionais aos Estados mais pobres, visando à promoção da capacitação institucional, social e econômica destes últimos (GOUVEIA, 2014).

O autor ressalva que o direito que vem a ser desenvolvido na Europa Ocidental assume uma natureza híbrida, posto que ora corresponde ao Direito Internacional, ora ao Direito Estadual, travando-se uma composição eclética que acaba por se converter em outro setor do Direito. Em verdade, sobretudo nos aspectos em que se evidencia o alicerce do Direito Internacional, o Direito da União Europeia se torna, de certa maneira, uma derivação moderna do anseio de integração transnacional axiomático do Direito Internacional (GOUVEIA, 2014).

Lembra-nos Martins (2012) que a UE, como comunidade europeia e como sujeito de direito internacional, reforça, em seus documentos, diversos direitos civis e políticos, buscando a proteção e a efetivação de direitos fundamentais. A Carta dos Direitos Fundamentais da União Europeia consta nesse quadro de afirmação de direitos das pessoas por parte da UE, afirmando, expressamente, que coloca o ser humano no cerne da sua ação. Cita, por exemplo, que a UE possui várias vertentes na política externa, a saber: a cooperação euromediterrânea, a parceria com os vizinhos mais próximos, em particular com os Estados que anteriormente faziam parte da ex-URSS, a ajuda ao desenvolvimento, a ajuda humanitária e a associação com terceiros. 
Nesse segmento, o artigo 21 do Tratado da União Europeia elenca as disposições gerais que regem a ação externa da União, a qual se estabelece nos princípios que presidiram a sua criação, desenvolvimento e alargamento, sendo também seu objetivo promover em todo o mundo: democracia, Estado de direito, universalidade e indivisibilidade dos direitos do homem e das liberdades fundamentais, respeito pela dignidade humana, princípios da igualdade e solidariedade e respeito pelos princípios da Carta das Nações Unidas e do direito internacional. Também deverá buscar desenvolver relações e constituir parcerias com os países terceiros e com as organizações internacionais, regionais ou mundiais que compactuem com os princípios supracitados, bem como promover soluções multilaterais para os problemas comuns, em especial no âmbito das Nações Unidas.

Nos termos do artigo 208 do Tratado de Funcionamento da União Europeia, a política da União em matéria de cooperação para o desenvolvimento será conduzida em concordância com os princípios e objetivos da ação externa da União, sendo o objetivo principal da política da União, neste domínio, a redução da pobreza, trabalhando, a longo prazo, para a erradicação. Quando em situações de aplicação de políticas suscetíveis de afetar os países em desenvolvimento, a União levará em conta os objetivos de cooperação para o desenvolvimento. A União e os Estados-Membros respeitarão os compromissos e considerarão os objetivos aprovados no âmbito das Nações Unidas e das demais organizações internacionais competentes.

Para Martins (2012), a UE tem desenvolvido uma atividade sólida de apoio ao desenvolvimento sustentável, nos planos econômico, social e ambiental de outros países há alguns anos. Vale dizer, a União 
tem proporcionado apoio à cooperação para o desenvolvimento desde 1957, e, atualmente, figura como o principal doador mundial de ajuda

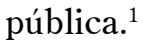

A posição da UE como principal fornecedor de ajuda pública para o desenvolvimento é reafirmada por Mah (2007), o qual entende que a política de cooperação para o desenvolvimento se constitui como base das relações entre a UE e os países em desenvolvimento e a aponta como um ator essencial no diálogo político internacional.

Sobre o assunto, deve-se considerar que, em 2005, a Comissão, o Conselho e o Parlamento aprovaram, em conjunto, o "Consenso Europeu sobre a Política de Desenvolvimento da União Europeia”. ${ }^{2}$ Tal declaração teve a finalidade de definir os princípios e valores que guiariam a política de cooperação para o desenvolvimento.

Outrossim, assevera o princípio da apropriação, qual seja, de que os países em desenvolvimento possuem uma responsabilidade precípua de criar uma conjuntura interna favorável à mobilização dos seus próprios recursos, adotando políticas coerentes e eficazes. Por seu turno, a UE cumprirá com o princípio da parceria, buscando fornecer uma assistência que se adeque às necessidades dos países beneficiários (MAH, 2007).

\footnotetext{
${ }^{1}$ Ver: JORNAL OFICIAL DA UNIÃO EUROPEIA. 9 de maio de 2014, PT, L 136/1 a L 136/9. Decisão $n^{\circ}$ 472/2014/EU do Parlamento Europeu e do Conselho de 16 de abril de 2014 sobre o Ano Europeu para o Desenvolvimento (2015). Disponível em: <http://www.europarl. europa.eu/meetdocs/2014_2019/documents/deve/dv/eyd2015_/eyd2015_pt.pdf. .Acesso em: 23 ago. 2015.

${ }^{2}$ Ver: UNIÃO EUROPÉIA. Secretariado Geral do Conselho da União Europeia, Declaração Conjunta do Conselho e dos Representantes dos Governos dos Estados-Membros reunidos no Conselho do Parlamento Europeu e da Comissão sobre política de desenvolvimento da EU: o consenso europeu. Bruxelas: Secretariado Geral do Conselho da União Européia, 2005. Disponível em: <http://eur-lex.europa.eu/legal-content/PT/TXT/?uri=uriserv:r12544>. Acesso em: 27 ago. 2015.
} 
Mah (2007) explica que o Consenso Europeu não possui força de lei e que, na prática, funciona como um documento de referência, pois ratifica um conjunto de intenções. Além disso, trata-se de documento que poderá ser utilizado como unificador dos sujeitos envolvidos, que possibilita um quadro geral para posterior debate sobre políticas públicas para a área da cooperação para o desenvolvimento, além de servir de base para monitoramento da instituição das políticas de cooperação.

De acordo com dados da Comissão Europeia, a ajuda fornecida pela UE entre os anos de 2004 e 2012 possibilitou que 18,3 milhões de crianças com menos de um ano de idade fossem vacinadas contra o sarampo; 13,7 milhões de crianças tivessem a oportunidade de frequentar o ensino básico; 24,5 milhões de pessoas tivessem acesso a instalações de saneamento básico; 46,5 milhões de pessoas se beneficiassem de transferências sociais para o combate à fome e à má-nutrição (PARLAMENTO..., 2015).

Considera-se que o lançamento dos Objetivos de Desenvolvimento do Milênio ocasionou uma mudança fundamental nos debates sobre o desenvolvimento global e na governação mundial, com mudanças, inclusive, no cenário econômico e político, a exemplo do crescimento de antigos países em desenvolvimento, como a China e o Brasil. Persistem, contudo, problemas como as desigualdades em âmbito mundial, as violações dos direitos humanos, a discriminação e as desigualdades de gênero, os conflitos armados e o terrorismo, alterações climáticas, insegurança alimentar, migração, desemprego, crescimento populacional e evolução demográfica, corrupção, escassez de recursos naturais, crescimento instável e crises financeiras e econômicas.

Vale afirmar que a Comissão Europeia indica que, no âmbito da cooperação para o desenvolvimento, o seu principal objetivo é assegurar que a ajuda fornecida pela UE chegue às pessoas que mais necessitam, dando ênfase aos direitos humanos, uma vez que consideram que estes configuram um meio e um fim na cooperação para o desenvolvimento. 
Para 2015, por meio da Comissão do Desenvolvimento, debateu-se a destinação de quase 5 milhões de euros do orçamento da UE, buscando alinhar outras políticas da UE com os objetivos de desenvolvimento do milênio (PARLAMENTO..., 2015).

O AED 2015 contou com uma agenda de eventos e atividades ao longo do ano. Dentre esses, seminários, debates, conferências, painéis, atividades culturais, concertos, manifestações desportivas, etc. Uma temática específica foi destinada a cada mês, compondo-se o calendário anual da seguinte forma:

a) janeiro - A Europa no mundo;

b) fevereiro - Educação;

c) março - Mulheres e raparigas;

d) abril - Saúde;

e) maio - Paz e segurança;

f) junho - Crescimento sustentável, emprego digno e empresas;

g) julho - Infância e juventude;

h) agosto - Ajuda humanitária;

i) setembro - Demografia e migração;

j) outubro - Segurança alimentar;

k) novembro - Desenvolvimento sustentável e alterações climáticas;

1) dezembro - Direitos humanos e governação.

Convém destacar, ainda, que a UE esteve e está envolvida em debates acerca de estratégias de desenvolvimento mesmo após 2015, por meio de consultas públicas, diálogos com parceiros estratégicos e extensa investigação. A Comissão Europeia concluiu pela adoção de cinco alicerces fundamentais que irão figurar entre os objetivos para erradicação da 
pobreza, desenvolvimento sustentável e garantia de uma vida digna a todos até 2030, quais sejam: condições de vida elementares para todos; promoção de "motores" de crescimento inclusivo e sustentável; gestão mais sustentável dos recursos naturais; igualdade, equidade e justiça; combate à insegurança e às fragilidades do Estado (COMISSÃO..., 2013).

Mah (2007) preleciona que, embora existam diversos debates sobre se o apoio fornecido a alguns países atrasa ou não o desenvolvimento, o que deve ser assegurado é que a ajuda internacional, por parte dos países desenvolvidos, bem como o aumento substancial que é esperado nos próximos anos, sejam utilizados de forma capaz de sanar as necessidades reais das populações locais. Com efeito, o que se observou durante um período foi uma agenda internacional que refletia apenas os interesses geoestratégicos e comerciais dos países doadores, das instituições financeiras internacionais, a exemplo do Banco Mundial ou do Fundo Monetário Internacional, ou a primazia da visão de quem concedia ajuda. Em verdade, apenas com um auxílio mais eficiente é que será possível alcançar um desenvolvimento sustentável e uma melhoria na qualidade de vida da população mundial.

Efetivamente, o fato de se ter uma agenda internacional refletindo apenas interesses geoestratégicos e comerciais de países doadores ou de instituições financeiras internacionais, conduz a uma observação importante: a relação crítica entre capitalismo, globalização e direitos humanos; isso porque o sistema de especulação financeira capitalista permitiu o rápido avanço da globalização econômica, e permitiu também a cisão entre economia e sociedade e o aumento das desigualdades sociais.

Flores (2009) já reforçava a necessidade de se construir uma racionalidade política, ética e social comprometida com os direitos humanos, em oposição a uma racionalidade hegemônica de mercado globalizada. Vejamos o seguinte exemplo: a Alemanha, ao mesmo tempo em que realiza investimentos para o desenvolvimento do Brasil e fomenta projetos 
de combate à pobreza, tem a maior parte de suas indústrias poluentes localizadas no Brasil e importa produtos in natura a baixos preços, como o café, para os industrializar.

Resta claro que os processos de "apoio", de "ajuda” para o desenvolvimento, desvelam relações antagônicas que afetam os direitos humanos. É preciso pensar sobre isso e, aproveitando as ideias de Flores (2009), fica o registro de sempre se deixar as diferenças às claras, sobretudo no tocante às ordens hegemônicas, adotando-se uma postura crítica em relação ao que é dado e que determina o funcionamento de todo o processo cultural.

Em 2014, Kris Mauren, cofundador e diretor executivo do Acton Institute, produziu o documentário “Pobreza S.A.”, que foi feito após um trabalho de 6 anos, com visitas a 28 países e entrevistas com mais de cem especialistas, de dentro e de fora da chamada “indústria da pobreza”. Para além disso, o documentário baseou-se em dados anualmente publicados sobre o tema, como o Index of Economic Freedom (índice de liberdade econômica), com dados empíricos sobre a pobreza em diferentes nações (POLITIZE, 2017).

O filme mostra os mecanismos que sustentam essa indústria e que contribuem para que as pessoas se tornem cada vez mais dependentes de ajuda humanitária. Mauren afirma existir uma grande e complexa indústria que ganha imensos lucros por meio da pobreza. Essa indústria é composta por governos, que fornecem recursos, grandes organizações não governamentais, que ficam com boa parte dos investimentos, e empresas de todos os tipos (POLITIZE, 2017). O ponto crucial é que políticas de assistência dessa natureza, que fornecem ajuda durante meses, anos e até décadas, não investem no desenvolvimento dos lugares necessitados, ou seja, não propiciam um desenvolvimento sustentável com respeito efetivo aos direitos humanos. 


\section{A PONDERAÇÃO DA CLÁUSULA DEMOCRÁTICA PARA A GARANTIA DE DIREITOS HUMANOS DIANTE DA CRISE EUROPEIA}

Ainda sobre as repercussões do Ano Europeu do Desenvolvimento é oportuno argumentar sobre a cláusula democrática para a garantia de direitos humanos firmada no âmbito da UE. Contudo, antes de debater acerca da cláusula cabe contextualizar, minimamente, a crise europeia.

Como destaca Silva (2015), em 2010 irrompeu na Europa a chamada crise da dívida soberana, em razão das dificuldades de alguns países europeus, como Grécia, Portugal, Irlanda, Itália e Espanha em pagar suas dívidas. Esta crise reflete a situação destes países até hoje, uma vez que não conseguem gerar crescimento econômico suficiente para cumprir os compromissos firmados perante seus credores ao longo dos anos, aumentando a dívida externa e interna.

A crise na Espanha, por exemplo, tem como consequência o acirramento do debate sobre a própria configuração do Estado espanhol, aguçando o movimento pela autodeterminação de algumas regiões. $\mathrm{O}$ caso da Catalunha exemplifica isso. Parte da população, e mesmo das elites de Itália, Espanha, Portugal e Grécia, fazem à Alemanha acusações pela sua escassa sensibilidade adiante da crise econômica e social; acusações que se estendem à Comissão Europeia e ao Banco Central Europeu. Inversamente, o governo alemão, e parte importante da população, de forma bi-partisan, entendem que não devem pagar os custos de outros países pela crise financeira a que chegaram. Ora, para os alemães, depois de terem aplicado políticas de austeridade ao longo de décadas, e, no caso, terem arcado com a reconstrução da antiga Alemanha Oriental, custos suplementares são considerados não suportáveis e politicamente inviáveis (VIGEVANI; ARAGUSUKU, 2013). 
Em dezembro de 2014 a Ocde divulgou o estudo "Trends in income inequality and its impact on economic growth", que revelou que a desigualdade entre ricos e pobres nos 34 países membros da organização atingiu o nível mais elevado em 30 anos. O rendimento de $10 \%$ da população mais rica é 9,5 vezes mais elevado que o de $10 \%$ dos mais pobres. Jamais o fosso entre ricos e pobres foi tão pronunciado nas economias avançadas (CINGANO, 2014).

Na década de 80 essa relação era de 7 para 1 e as desigualdades de rendimentos aumentaram sobretudo a partir de meados dessa década. Ainda segundo este estudo, as desigualdades de rendimento comprometem a igualdade de oportunidades no plano da educação e limitam a mobilidade social e profissional, e as conclusões que os decisores políticos daí podem retirar são as de que o propósito de pugnar por mais crescimento deve seguir a par da luta contra as desigualdades (CINGANO, 2014).

Diante desses problemas e do cenário de desigualdades crescentes, as medidas de austeridade despontam e são adotadas pelos países europeus em crise. Ocorre que elas reduzem os direitos sociais, afrontando a cláusula democrática firmada no âmbito da UE (WÜNSCH; WÜNSCH, 2013).

Figueiredo (2007) acredita que a democracia está para além dessas condições institucionais. Para ele,

[...] deve-se compreender a ideia de que a violação de algum direito econômico, social ou cultural sempre acarretará a infringência aos direitos civis e políticos, porquanto a hipossuficiência econômico-social conduz à vulnerabilidade no gozo dos direitos civis e políticos (p. 32).

Aqui vale lembrar que no processo de modernização social do Direito, a democracia passou a ocupar um lugar central, pois, como defende Habermas (2002), não há Estado de Direito sem democracia e vice-versa. Para o autor, a relação interna entre Estado de Direito e demo- 
cracia resulta do próprio conceito moderno de direito e da circunstância de que o Direito positivo (histórico, conceitual, modificável e coercitivo) não pode mais obter legitimidade recorrendo a um Direito natural, superior.

Habermas (2002) entende que uma ordem jurídica é definida como legítima quando assegura, de forma equitativa, a autonomia de todos os cidadãos. Para ser legítimo, é preciso que o direito seja produzido de maneira democrática. Não é possível se falar em sujeitos de direito sem considerar que sejam também cidadãos livres e iguais. Por outro lado, não há de se falar em cidadãos livres e iguais sem reconhecer que sejam, ao mesmo tempo, sujeitos de direito. Ou seja, há uma coesão interna entre direitos humanos, representados pelo núcleo da autonomia privada, e soberania popular, representada pelo núcleo da autonomia pública.

A ideia de autodeterminação exige que os destinatários do direito possam, ao mesmo tempo, ver-se como seus autores, e pressupõe a autonomia pública e privada mutuamente. Os cidadãos somente podem fazer um uso adequado de sua autonomia pública quando são independentes o bastante, em razão de uma autonomia privada que esteja equanimente assegurada, mas também no fato de que apenas poderão chegar a uma regulamentação capaz de gerar consenso se fizerem uso adequado de sua autonomia política como cidadãos (HABERMAS, 2002).

Assim, quando Figueiredo (2007) trata da ideia de que a violação de direito econômico, social ou cultural acarreta infringência aos direitos civis e políticos, está abordando a violação da autonomia privada e da autonomia pública em prejuízo à democracia e ao Estado Democrático de Direito.

Pois bem, de fato o processo de integração da Europa, por meio da Constituição da União Europeia, enfatizou preliminarmente aspectos econômicos e comerciais. As demais dimensões, como as culturais, sociais e as políticas, tiveram uma evolução mais lenta, como indicam os tratados 
e programas de cooperação. A condicionalidade política da cláusula democrática como requisito para integrar a União Europeia é um exemplo disso (WÜNSCH; WÜNSCH, 2013).

A cláusula democrática obriga os seus contratantes a promoverem a democracia e a respeitarem os direitos humanos além da efetivação da cooperação política e econômica. Esse compromisso com o desenvolvimento social, econômico e cultural, mediante a promoção da democracia, da erradicação da pobreza, da solidariedade, da autodeterminação e da não intervenção nos países, encontra-se explicitado em diversos tratados da então Comunidade Europeia e atual União Europeia (WÜNSCH; WÜNSCH, 2013).

Esta cláusula foi referida no preâmbulo do Tratado da União Europeia, mas na década de 90 a UE adotou os Critérios de Copenhague, aprovados pelo Conselho Europeu em 1993, os quais estabeleceram explicitamente condicionalidades que os Estados que desejassem aderir ao Bloco deveriam preencher, tais como:

a) Dispor de instituições estáveis, garantindo a democracia, a primazia do direito, os Direitos Humanos, o respeito das minorias e sua proteção;

b) Dispor de uma economia de mercado viável e capaz de enfrentar a concorrência e participar do dinamismo do mercado interno da União;

c) Dispor de instituições suscetíveis de assegurar o cumprimento das obrigações decorrentes da adesão à União, a adoção e a observância do acquis comunitário e de engajar-se nos objetivos da união política, econômica e monetária (CRITÉRIOS..., 1993).

É de se notar que os Critérios de Copenhague ampliaram e explicitaram a cláusula democrática. Essa decisão do Conselho Europeu teve por base o artigo 49 do Tratado da União Europeia de 1992 a respeito das condições a serem adotadas no processo de adesão de novos Estados-membros (WÜNSCH; WÜNSCH, 2013). 
Campos (2004, p. 271) expõe o princípio democrático no Tratado da União Europeia:

[...] o princípio identifica-se com uma determinada concepção sobre a legitimidade, a organização e o exercício do poder político e encontra a sua expressão no sistema da democracia representativa e pluralista. Paralelamente, como expressão de uma exigência irrecusável nos planos ético, social e político, o princípio democrático implica o respeito dos direitos fundamentais tal como estes são enunciados e salvaguardados não só em algumas disposições dos Tratados, mas, sobretudo, nas Constituições dos Estados-membros e nos instrumentos internacionais que os Estados aderiram.

Wünsch e Wünsch (2013) asseveram que a exigência da democracia representativa e pluralista como base da salvaguarda dos direitos fundamentais, gradativamente se consolidou enquanto compromisso e exigência da União Europeia, especialmente diante do alargamento em relação à adesão de novos Estados-membros e da necessidade de aperfeiçoamento do processo de integração.

Sobre o tema, o Tratado de Nice, em vigor a partir de 2003, assegurou que o Conselho Europeu pode verificar o risco manifesto de violação grave dos direitos fundamentais e da condicionalidade política com o propósito de lhes dirigir recomendações apropriadas, o que é considerado pelos doutrinadores um aviso prévio à condicionalidade política, pois o Conselho Europeu, ao verificar um risco manifesto de violação grave dos direitos fundamentais, pode dirigir aos Estados recomendações apropriadas para evitar que a cláusula democrática seja violada (WÜNSCH; WÜNSCH, 2013).

Em tempos de crise, o risco de violação à cláusula democrática com base nessa compreensão é real, à medida que os efeitos da globalização acentuados pela crise têm consequências sociais graves, especialmente por meio da "flexibilização" de direitos fundamentais. 
Para Sarlet (2015), dentre os diversos efeitos perversos da crise e da globalização econômica, situa-se a disseminação de políticas de "flexibilização" e até mesmo supressão de garantias dos trabalhadores (sem falar no crescimento dos níveis de desemprego e índices de subemprego), redução dos níveis de prestação social, desmantelamento dos sistemas públicos de saúde, aumento desproporcional de contribuições sociais por parte dos participantes do sistema de proteção social, incremento da exclusão social e das desigualdades, entre outros aspectos.

O Estado Democrático de Direito deve proteger a segurança jurídica das pessoas, ou seja, a segurança dos cidadãos de que seus direitos conquistados serão mantidos, pois a cláusula democrática não deve servir somente aos fins do interesse econômico, mas também aos direitos dos cidadãos europeus (WÜNSCH; WÜNSCH, 2013).

Não se pode diminuir o nível de proteção desses direitos por intermédio da legislação ou de medidas políticas e jurídicas. Por conseguinte, é relevante destacar o papel da população na esfera das políticas públicas, mediante mecanismos de participação e controle jurisdicional dos atos do poder público, sobretudo quando se trata de medidas de caráter regressivo de direitos, uma vez que tais medidas não podem, em momento algum, mesmo em tempo de crise, afastar o compromisso do Estado Democrático e Social de Direito com a garantia de uma existência digna para todos (WÜNSCH; WÜNSCH, 2013).

Nesta seara, o reconhecimento ao princípio da proibição de retrocesso significa a manutenção de um patamar básico tanto em termos de proteção social quanto de segurança jurídica. Para Cook (1990, p. 683), “o princípio da proibição de retrocesso está implícito nas convenções sobre direitos do homem”. O não retrocesso dos direitos do homem é mais do que implícito, é ético, prático e quase judiciário. Resulta em uma obrigação 
positiva para os Estados. Assim, a proibição do retrocesso, apesar de sua aparência de obrigação negativa, conduz a uma obrigação positiva aplicada a um direito fundamental.

A crise da Europa e os retrocessos profundos e rápidos de direitos nos países em crise expõem um cenário em que a supervalorização das instituições financeiras e a busca do crescimento econômico não eliminaram as contradições, as desigualdades sociais e econômicas, nem o desenvolvimento desigual entre as nações. Ao contrário, acentuam as contradições, as desigualdades sociais e o desenvolvimento desigual entre elas, e elevam as disputas e a concorrência em razão da direção desse processo, principalmente pela lógica do capital financeiro (VIGEVANI; ARAGUSUKU, 2013).

Refletindo sobre o tema, Habermas (2011) acredita que essa "homogeneidade”, pretendida no âmbito da UE, assenta apenas numa estimativa das situações de vida social que seja aceitável do ponto de vista da justiça da repartição - e não no nivelamento das diferenças culturais. Acontece que é necessária uma integração política baseada no bem-estar social para que a pluralidade nacional e a riqueza cultural do biótopo da "velha Europa” possam ser protegidas do nivelamento no seio de uma globalização, cuja progressão é tensa.

Por certo, ainda que os tratados da União Europeia prevejam normas de conteúdo político e social que reforcem a democracia, o privilégio a questões econômicas e financeiras é patente. $\mathrm{O}$ desafio de efetuar uma integração política baseada no bem-estar social em meio à pluralidade nacional implica a construção de normas jurídicas que assegurem aos direitos humanos o respeito à diversidade manifesta localmente e contribuam para superar as desigualdades (VIGEVANI; ARAGUSUKU, 2013).

O uso da cláusula democrática pela União Europeia tem um papel fundante e é isto que se defende no presente trabalho. A crise “[...] é a possibilidade que podemos testar: a democracia para além da política” 
(RIBEIRO, 2010, p. 135), é o momento de analisar as consequências do papel das instituições financeiras e de um projeto de integração sem a devida consideração com as desigualdades, ainda que haja uma institucionalidade “democrática” na Europa.

Vigevani e Aragusuku (2013) defendem que políticas de combate às desigualdades, no que se relacionam à integração regional, têm a ver com uma concepção de mundo na qual a solidariedade tem um papel político e econômico, além de moral. Assim, a integração não pode se restringir à política de mercado, não desprezível, e deve-se ter em conta o fator econômico, mas também buscar unificar vida política, cultura e sociedade. Quando existirem progressos nesses campos também existirão melhoras no ambiente integracionista.

\section{CONCLUSÃO}

Concluiu-se que:

Diante da crise europeia, o Ano Europeu do Desenvolvimento trouxe uma oportunidade para se (re)pensar as ações de combate à intensificação das desigualdades internas na União Europeia, fazendo valer o intento do Direito Comunitário de propiciar integração com valorização da dignidade humana, com vistas a uma sociedade democrática, fraterna e solidária.

Como já abordado, em tempos de crise o risco de violação à cláusula democrática é patente, e assiste-se à “flexibilização" de direitos humanos em países europeus. Não por outra razão, o uso da cláusula democrática assumiu um papel fundante, pois as dificuldades econômicas fomentaram e fomentam o debate acerca da diminuição da proteção de direitos via legislação ou medidas políticas, e ajudam a constatar que a proibição 
de retrocesso, presente em várias convenções sobre direitos do homem, corresponde à manutenção de um patamar básico em termos de direitos humanos, proteção social e segurança jurídica.

De fato, o Ano Europeu do Desenvolvimento abriu oportunidades para que a União Europeia (re)pense suas políticas públicas internas de cooperação e, ademais, re(pense) a sua agenda internacional de apoio ao desenvolvimento para que, dentre as limitações em razão do mercado, não reflita apenas os interesses geoestratégicos e comerciais dos países doadores ou das instituições financeiras internacionais (MAH, 2007);

As ações de apoio ao desenvolvimento sustentável, nos planos econômico, social e ambiental, voltadas aos países em desenvolvimento, suscitam uma reflexão de como superar políticas meramente assistenciais, transformando-as em políticas garantidoras de oportunidades reais de desenvolvimento, o que se acredita somente será alcançado a partir de processos contextualizados com as realidades locais, que sejam inovadores e dialógicos.

Dia após dia despontam as mais desencontradas especulações a respeito do futuro da Europa. Silva (2015) enfatizou a busca da paz como objetivo da construção da União Europeia, a qual foi atingida por um espírito de solidariedade que parece ter-se perdido com o passar dos anos. Nessa senda, Fiori (2011) ressaltou a perda de valores “intangíveis”, pois parece que os valores nada mais representam e que os mercados tudo podem. Ainda assim, pouco se fala dos custos intangíveis do fracasso europeu no campo das ideias, dos valores e dos grandes sonhos e símbolos que movem a humanidade. Pouco se comenta acerca do impacto sobre duas pilastras fundamentais do pensamento moderno: a crença na viabilidade contratual de um governo ou governança mundial; e a aposta na possibilidade cosmopolita de uma federação ou confederação de repúblicas, pacíficas, harmoniosas, e sem fronteiras ou egoísmos nacionais. Duas ideais europeias que foram concebidas num continente extremamente 
belicoso e competitivo, "mas que foi o grande responsável pela criação e universalização do sistema de estados nacionais modernos e do próprio capitalismo" (FIORI, 2011, p. 2).

\section{REFERÊNCIAS}

ANO EUROPEU DO DESENVOLVIMENTO. Disponível em: $<$ https://europa. eu/eyd2015/pt-pt>. Acesso em: $1^{\circ}$ jul. 2015.

CAMPOS, João Mota de. Manual de direito comunitário: o sistema institucional, a ordem jurídica e o ordenamento econômico da União Européia. 4. ed. Lisboa: FCG, 2004.

CARTA DAS NAÇÕES UNIDAS E ESTATUTO DA CORTE INTERNACIONAL DE JUSTIÇA. Disponível em: <http://unicrio.org.br/img/CartadaONU_ VersoInternet.pdf>. Acesso em: $1^{0}$ jul. 2015.

CINGANO, F. Trends in Income Inequality and its Impact on Economic Growth, OECD Social, Employment and Migration Working Papers, $\mathrm{n}^{\circ}$ 163, OECD Publishing, 2014. Disponível em: <http://dx.doi.org/10.1787/5jxrjncwxv6j-en>. Acesso em: 31 jul. 2015.

COOK, Rebecca J. Reservation to the convention on the elimination of allforms of discrimation against women. Virginia Journal of International Law, Virginia, vol. 30, 1990.

CRITÉRIOS DE COPENHAGUE, 1993. Disponível em: <http://europa.eu/ legislation_summaries/glossary/accession_criteria_copenhague_en.htm>. Acesso em: 7 ago. 2015.

COMISSÃO EUROPÉIA. A contribuição da UE para os objetivos de desenvolvimento do milênio: alguns resultados importantes dos programas da Comissão Européia, 2013. Disponível em: <http://www.igfse.pt/upload/docs/2015/ContribuicaoUEparaObjetivosMilenio.pdf $>$. Acesso em: 27 ago. 2015.

DUARTE, Maria Luísa. Direito internacional público e ordem jurídica global do século XXI. Coimbra: Coimbra Editora, 2014. 
FIGUEIREDO, Mariana Filchtiner. Direito fundamental à saúde: parâmetros para sua eficácia e efetividade. Porto Alegre: Livraria do Advogado, 2007.

FIORI, José Luís. O custo intangível do fracasso europeu. Valor, 22 nov. 2011. Disponível em: <http://outraspalavras.net/posts/o-custo-intangivel-do-fracasso-europeu/>. Acesso em: 23 ago. 2015.

FLORES, Joaquín Herrera. Teoria crítica dos direitos humanos: os direitos humanos como produtos culturais. Rio de Janeiro: Ed. Lumen Juris, 2009.

GOUVEIA, Jorge Bacelar. Manual de direito internacional público. 4. ed. Coimbra: Almedina, 2014.

HABERMAS, Jürgen. A inclusão do outro: estudos de teoria política. Trad. George Sperber e Paulo Astor Soethe. São Paulo: Loyola, 2002.

Está em jogo a democracia. 2011. Disponível em: <http://www.presseurop.eu/pt/content/article/1106151-juergen-habermas-esta-em-jogo-democracia>. Acesso em: 23 ago. 2015.

JORNAL OFICIAL DA UNIÃO EUROPEIA. 7 de jun. de 2016, PT, C 202/13 a C 202/45. Tratado da União Europeia (versão consolidada). Disponível em: $<$ http://eur-lex.europa.eu/resource.html?uri=cellar:9e8d52e1-2c70-11e6-b49701aa75ed71a1.0019.01/DOC_2\&format=PDF >. Acesso em: 25 set. 2017.

. 9 de maio de 2014, PT, L 136/1 a L 136/9. Decisão nº 472/2014/EU do Parlamento Europeu e do Conselho de 16 de abril de 2014 sobre o Ano Europeu para o Desenvolvimento (2015). Disponível em: $<$ http://www.europarl.europa. eu/meetdocs/2014_2019/documents/deve/dv/eyd2015_/eyd2015_pt.pdf . Acesso em: 23 ago. 2015.

JORNAL OFICIAL DAS COMUNIDADES EUROPÉIAS. 10 mar. 2001, PT, C 80/1 a C 80/87. Tratado de Nice. Disponível em: <https://www.ecb.europa. eu/ecb/legal/pdf/pt_nice.pdf $>$. Acesso em: 23 ago. 2015.

18 dez. 2000, PT, C 364/1 a C 364/22. Carta dos Direitos Fundamentais da União Européia. Disponível em: <http://www.europarl.europa.eu/charter/ pdf/text_pt.pdf $>$. Acesso em: 23 ago. 2015. 
LEWANDOVSKI, Enrique Ricardo. Direito comunitário e soberania: algumas reflexões. p. 231-242, dez. 1997. Disponível em: <http://www.revistas.usp.br/ rfdusp/article/viewFile/67362/69972>. Acesso em: 15 ago. 2015.

LIMA FILHO, Francisco das C. A ordem jurídica comunitária européia: princípios e fontes. Revista Jurídica Unigran, Dourados, MS, v. 8, n. 15, p. 75-115, jan./jun. 2006.

MARTINS, Ana Maria Guerra. Manual de Direito da União Européia. Coimbra: Almedina, 2012.

MARTINS, Etiene. Princípios de direito comunitário. Centro Científico Conhecer. Enciclopédia Biosfera, Goiânia, GO, n. 7, p. 1-5, 2009.

M. JÚNIOR, Henrique Douglas M. Direito comunitário e a legitimidade das normas internacionais públicas. Arquivo Jurídico, v. 1, n. 1, p. 159-169, jul./ dez. 2011.

MAH, Luís. Um novo paradigma europeu na cooperação para o desenvolvimento. Relações Internacionais, Lisboa, v. 14, p. 67-73, 2007.

NAÇÕES UNIDAS. Declaração do Milênio. Resolução A/RES/55/2, de 8 de setembro de 2000. Disponível em: <https://www.unric.org/html/portuguese/ uninfo/DecdoMil.pdf $>$. Acesso em: 23 ago. 2015.

PARLAMENTO EUROPEU. O Parlamento Europeu está empenhado no desenvolvimento. 2015. Disponível em: <http://www.igfse.pt/upload/docs/2015/ OParlamentoEuropeuestaempenhadonodesenvolvimento.pdf $>$. Acesso em: 23 ago. 2015.

PIMENTA, Carlos. A Europa e o desenvolvimento. Cadernos de Economia, p. 15-18, jan./mar. 2015. Disponível em: <http://www.gestaodefraude.eu/wordpress/wp-content/uploads/2015/03/EuroDes.pdf>. Acesso em: 30 jul. 2015.

POLITIZE. Ajuda humanitária: solidariedade ou indústria da pobreza? Disponivel em: <http://www.politize.com.br/ajuda-humanitaria-solidariedade-ou-industria-da-pobreza/>. Acesso em: 25 set. 2017.

QUEIROZ, Cristina. Direito internacional e relações internacionais. Coimbra: Coimbra Editora, 2009. 
RIBEIRO, Renato Janine. Democracia. In: BARRETO, Vicente de Paulo. Dicionário de filosofia política. São Leopoldo: Ed. Unisinos, 2010.

SARLET, Ingo Wolfgang. Algumas notas a respeito dos direitos fundamentais sociais e a proibição de retrocesso: desafios e perspectivas. Disponível em: <http://www.amatra4.org.br/cadernos/263-caderno-13?start=3>. Acesso em: 20 ago. 2015.

SILVA, Luiz Afonso Simoens da. A crise da Zona Euro e o sistema financeiro europeu. Disponível em: <http://www.ipea.gov.br/agencia/images/stories/ PDFs/artigos/120106_artigodintepanoramaeuropeu.pdf $>$. Acesso em: 15 ago. 2015.

UNIÃO EUROPÉIA. Secretariado-Geral do Conselho da União Europeia, Declaração Conjunta do Conselho e dos Representantes dos Governos dos Estados-Membros reunidos no Conselho do Parlamento Europeu e da Comissão sobre politica de desenvolvimento da EU: o consenso europeu. Bruxelas: Secretariado Geral do Conselho da União Européia, 2005. Disponível em: <http://eur-lex. europa.eu/legal-content/PT/TXT/?uri=uriserv:r12544>. Acesso em: 27 ago. 2015.

VIGEVANI, Tullo; ARAGUSUKU, Juliano A. S. A relação entre integração regional e questões sociais: combate à pobreza no Mercosul, considerando a União Européia. Dossiês Relação Brasil-Europa. Revista UFG, ano XIII, n. 14, p. 83-106, dez. 2013.

WÜNSCH, Marina Sanches; WÜNSCH, Paulo Roberto. A crise na União Europeia e seus reflexos na cláusula democrática e nos direitos fundamentais sociais. Espaço Jurídico Journal of Law. EJJL. Chapecó, v. 14, n. 2, p. 535-554, jul./dez. 2013. Disponível em: <http://editora.unoesc.edu.br/index.php/ espacojuridico/article/view/2716/2099>. Acesso em: 30 jul. 2015. 